\title{
Transverse piezoelectric coefficient measurement of flexible lead zirconate titanate thin films
}

\author{
T. Dufay, ${ }^{1}$ B. Guiffard, ${ }^{1}$ J.-C. Thomas,${ }^{2}$ and R. Seveno ${ }^{1}$ \\ ${ }^{1}$ LUNAM Université, Université de Nantes, IETR (Institut d'Électronique et de Télécommunications de \\ Rennes), UMR CNRS 6164, 2 rue de la Houssinière, BP 92208, 44322 Nantes Cedex 3, France \\ ${ }^{2}$ LUNAM Université, Université de Nantes-École Centrale Nantes, GeM (Institut de Recherche en Génie Civil \\ et Ingénierie Mécanique), UMR CNRS 6183, 2 rue de la Houssinière, BP 92208, 44322 Nantes Cedex 3, \\ France
}

Highly flexible lead zirconate titanate, $\mathrm{Pb}(\mathrm{Zr}, \mathrm{Ti}) \mathrm{O}_{3}$ ( $\mathrm{PZT}$ ), thin films have been realized by modified sol-gel process. The transverse piezoelectric coefficient $d_{31}$ was determined from the tip displacement of bending-mode actuators made of PZT cantilever deposited onto bare or $\mathrm{RuO}_{2}$ coated aluminium substrate ( $16 \mu \mathrm{m}$ thick). The influence of the thickness of ruthenium dioxide $\mathrm{RuO}_{2}$ and $\mathrm{PZT}$ layers was investigated for $\mathrm{Pb}\left(\mathrm{Zr}_{0.57} \mathrm{Ti}_{0.43}\right) \mathrm{O}_{3}$. The modification of $\mathrm{Zr} / \mathrm{Ti}$ ratio from $40 / 60$ to $60 / 40$ was done for $3 \mu \mathrm{m}$ thick PZT thin films onto aluminium (Al) and $\mathrm{Al} / \mathrm{RuO}_{2}$ substrates. A laser vibrometer was used to measure the beam displacement under controlled electric field. The experimental results were fitted in order to find the piezoelectric coefficient. Very large tip deflections of about $1 \mathrm{~mm}$ under low voltage $(\sim 8 \mathrm{~V})$ were measured for every cantilevers at the resonance frequency $(\sim 180 \mathrm{~Hz})$. For a given $\mathrm{Zr} / \mathrm{Ti}$ ratio of $58 / 42$, it was found that the addition of a $40 \mathrm{~nm}$ thick $\mathrm{RuO}_{2}$ interfacial layer between the aluminium substrate and the PZT layer induces a remarkable increase of the $d_{31}$ coefficient by a factor of 2.7 , thus corresponding to a maximal $d_{31}$ value of $33 \mathrm{pC} / \mathrm{N}$. These results make the recently developed PZT/Al thin films very attractive for both low frequency bending mode actuating applications and vibrating energy harvesting.

\section{INTRODUCTION}

Energy harvesting from ambient and low frequency mechanical vibration is actively studied because of source accessibility. Walking, ${ }^{1}$ dancing, ${ }^{2}$ or using the vibration produced by a bus ${ }^{3}$ are some examples of energy harvesting projects based on piezoelectricity.

Recent developments in low-power electronics may enable micropower energy harvesting to eliminate wiring, in order to reduce maintenance costs, or to replace electrochemical batteries. ${ }^{4}$ Piezoelectric materials convert efficiently the mechanical strain to an electrical charge and could generate enough power to charge batteries of some sensors (e.g., fatigue sensors). ${ }^{5}$ This is the reason why piezoelectric materials are widely studied for vibrating energy harvesting. ${ }^{6-9}$

Concerning piezoelectric thin films, several materials such as $\mathrm{Pb}(\mathrm{Zr}, \mathrm{Ti}) \mathrm{O}_{3}$ (PZT), $\mathrm{ZnO}$, and AlN are studied for actuating or sensing issues. ${ }^{10-12}$ Due to their superior ferroelectric and piezoelectric properties, PZT is the most attractive candidate. ${ }^{13}$ However, depending on the used substrate and the composition of the PZT thin film, ferroelectric and piezoelectric properties evolve. This is why the investigation of piezoelectric coefficient, and especially the transverse piezoelectric coefficient, is an important step for the characterization of a new material. Numerous methods for measuring the transverse piezoelectric coefficient have already been reported. ${ }^{14-16}$ Measurement of $d_{31}$ piezoelectric coefficient for PZT thin film as a function of the $\mathrm{Zr} / \mathrm{Ti}$ ratio is interesting to determine phase transition effects on film properties. For bulk PZT, it is well known that maximum ferroelectric and piezoelectric properties are obtained at the morphotropic phase boundary (MPB) composition. ${ }^{17}$ The MPB corresponds to the coexistence of the rhombohedral and the tetragonal phases of the PZT. For bulk PZT, even if it depends on many factors such as elaboration process, the MPB generally corresponds to $\mathrm{Zr} / \mathrm{Ti}$ ratios close to $52 / 48 .{ }^{18}$ But, the properties of thin films show different trends than those of bulk ceramics, due to substrate, interfacial layer, and film thickness influences. ${ }^{19,20}$ So, the investigation of ferroelectric and piezoelectric properties as a function of $\mathrm{Zr} / \mathrm{Ti}$ ratio for a new PZT thin film is a major improvement in understanding this material. In this paper, we report on the ferroelectric and piezoelectric characterization of newly developed PZT thin film $(\sim 3 \mu$ m thick) deposited by modified sol-gel process onto commercial aluminium foil with $16 \mu \mathrm{m}$ in thickness. ${ }^{21}$ Those flexible thin films are cheap (substrate cost $<0.1 \$ \mathrm{~m}^{-2}$ ) and could be easily used on different supports like vehicle in movement, aeration sheath, windmill, or any other structure exposed to wind, as aeroelastic energy harvester.

The study mainly focuses on the influence of both an intermediate ruthenium dioxide between PZT layer and aluminium substrate and the $\mathrm{Zr} / \mathrm{Ti}$ ratio on the intrinsic properties of the thin film. More specifically, ferroelectric properties (coercive field and remnant polarization) and transverse $d_{31}$ piezoelectric coefficients are determined for PZT/Al thin films with/without $\mathrm{RuO}_{2}$ and as a function of the interfacial layer thickness, using bending mode cantilever configuration. 


\section{EXPERIMENTAL}

PZT thin films were elaborated by a modified sol-gel process commonly used in the laboratory. Lead acetate $\left[\mathrm{Pb}\left(\mathrm{CH}_{3} \mathrm{CO}_{2}\right)_{2}, 3 \mathrm{H}_{2} \mathrm{O}\right]$, zirconium n-propoxide $\mathrm{Zr}\left(\mathrm{C}_{3} \mathrm{H}_{7} \mathrm{O}\right)_{4}$, and titanium n-propoxide $\left(\mathrm{Ti}\left(\mathrm{CH}_{3}\right)_{2} \mathrm{CHO}\right)_{4}$ are used as precursor materials. Acetic acid is used as solvent and ethylene glycol as an additive to prevent cracking.

Lead acetate is dissolved in heated acetic acid. Zirconium and titanium propoxides are mixed and then added to the lead acetate solution. The precursor solution is ready after the addition of the ethylene glycol. More technical details of the preparation of the precursor solution are reported elsewhere. ${ }^{22}$ The deposition process of the PZT thin film is given in Fig. 1. Multiple spin-coating technique at $6000 \mathrm{rpm}$ was performed to obtain a film thickness between 1.8 and $4.2 \mu \mathrm{m}$. Each single layer successively deposited is crystallized at $650{ }^{\circ} \mathrm{C}$ during $2 \mathrm{~min}$ and is about $300 \mathrm{~nm}$ thick. The $\mathrm{Zr} / \mathrm{Ti}$ ratio is modified with the proportion of precursor solutions. In both cases, i.e., bare and $\mathrm{RuO}_{2}$ coated aluminium, the PZT composition changes from $\mathrm{Zr} / \mathrm{Ti}=40 / 60$ to $\mathrm{Zr} / \mathrm{Ti}=60 / 40$. Ruthenium dioxide films were prepared by mixing and stirring a ruthenium (III) nitrosylnitrate $\left[\mathrm{Ru}(\mathrm{NO})\left(\mathrm{NO}_{3}\right)_{3}\right]$ aqueous solution and 2-methoxyethanol $\left[\mathrm{CH}_{3} \mathrm{O}\left(\mathrm{CH}_{2}\right)_{2} \mathrm{OH}\right]$. The final solution is then spin-coated on aluminium foil and fired at $450{ }^{\circ} \mathrm{C}$ in an open air furnace. ${ }^{23}$ This $\mathrm{RuO}_{2}$ layer was used in a previous work to improve the dielectric properties of the thin films with stainless steel substrate. ${ }^{23}$ Large-area $(1 \mathrm{~cm} \times 3 \mathrm{~mm})$ aluminium top electrodes with $300 \mathrm{~nm}$ in thickness were evaporated through a shadow mask on each sample. The substrate was directly used as the bottom electrode. Top view and schematic front view of thin films are given in Fig. 2.

Scanning electron microscopy (SEM) observations were carried out to check the thickness and structure of the PZT layer. Carl Zeiss Merlin SEM was used with electron energy set to $3 \mathrm{keV}$.

Samples must be poled to exhibit macroscopic piezoelectric properties. A Sawyer-Tower circuit was employed for both poling and investigation of polarization $P$ versus electric field $E$. An electric field frequency of $50 \mathrm{~Hz}$ was used. In order to protect samples from dielectric breakdown, the magnitude of the applied electric field was slowly increased.

Dielectric properties were investigated with an impedance meter Agilent $4294 \mathrm{~A}$. Loss factor $\tan \delta$ and relative dielectric permittivity $\varepsilon_{r}$ were measured at $1 \mathrm{kHz}$.

To determine the transverse piezoelectric coefficient $d_{31}$, cantilevers were clamped at one end. Dimensions of the free-part were measured with a precision of $0.5 \mathrm{~mm}$. Cantilever tip displacements were evaluated with a laser vibrometer OFV-2200 (Polytec) under an applied sinusoidal voltage of magnitude $V_{0}$ at different frequencies. A mathematical model is used to fit the experimental data and extract the quasistatic displacement $d_{0}$, the natural vibration

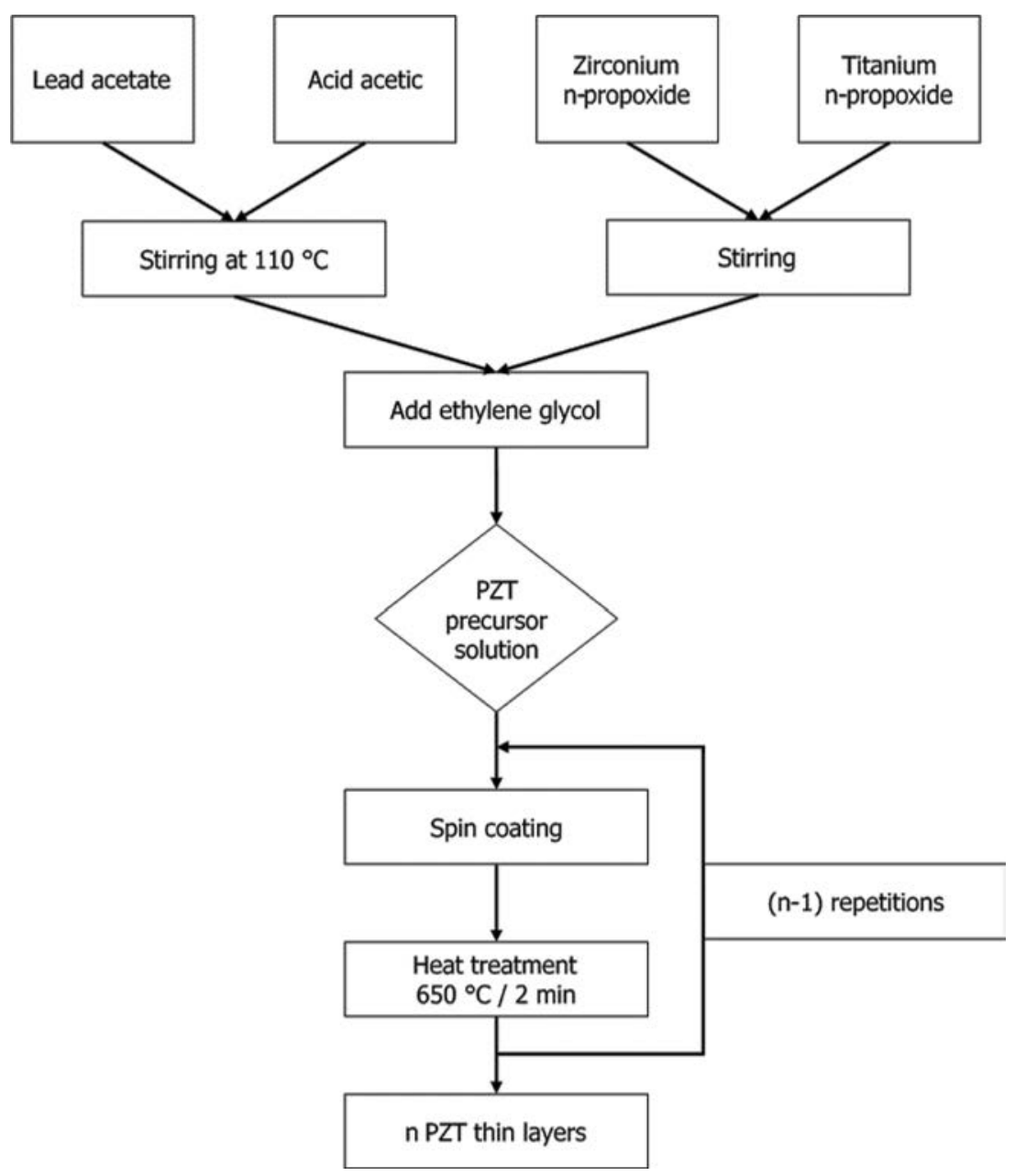

FIG. 1. Deposition process of the PZT thin film. 


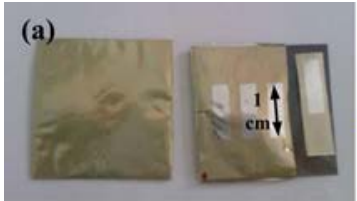

(b)

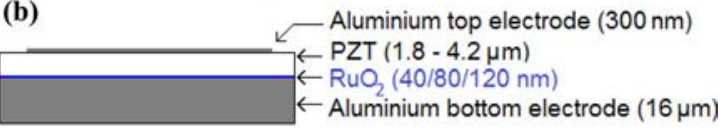

FIG. 2. Top view (a) and schematic front view (b) of thin films. frequency $f_{0}$, and the quality factor $Q$. Linear fit of $d_{0}$ versus applied voltage is exploited to find the $d_{31}$.

\section{RESULTS AND DISCUSSION}

SEM images of PZT 40/60 are shown in Fig. 3. PZT layer thickness is measured on the front view. A granular structure is seen and grains size is comprised between 100 and $300 \mathrm{~nm}$ as it could be observed on surface view. SEM study was done for three $\mathrm{Zr} / \mathrm{Ti}$ ratios: 40/60, 50/50, and 60/ 40 and for each ratio, two samples were observed. It appeared that $\mathrm{Zr} / \mathrm{Ti}$ ratio has no influence on the morphological structure.

\section{A. Influence of $\mathrm{RuO}_{2}$ layer thickness on the electrical properties of PZT thin films}

Measurement of electrical properties was done for PZT thin films with three different ruthenium dioxide $\left(\mathrm{RuO}_{2}\right)$ layer thicknesses: 40, 80, and $120 \mathrm{~nm}$. Dielectric and ferroelectric properties were investigated to evaluate the influence of $\mathrm{RuO}_{2}$ thickness. For this study, the $\mathrm{Zr} / \mathrm{Ti}$ ratio was fixed to $57 / 43$, which is a commonly used ratio at the laboratory and in the vicinity of the MPB. The study of the influence of $\mathrm{Zr} / \mathrm{Ti}$ on the electrical/piezoelectric properties will be presented in Sec. III C.

The $P$-E hysteresis loops, remnant polarization $\left(P_{r}\right)$, coercive field $\left(E_{c}\right)$, dielectric permittivity $\left(\varepsilon_{r}\right)$, and loss factor $(\tan \delta)$ of $3 \mu \mathrm{m}$-thick PZT 57/43 thin films with different thicknesses of $\mathrm{RuO}_{2}$ are given in Fig. 4. At an applied electric field of $167 \mathrm{kV} / \mathrm{cm}$, samples with a deliberately added intermediate oxide layer show a reasonably square wellsaturated hysteresis loop, whereas without $\mathrm{RuO}_{2}$, the hysteresis loop is not saturated. Here, the choice was made to apply the same electric field to the samples, even if the hysteresis loop without $\mathrm{RuO}_{2}$ is not saturated.

It has been shown that preparing PZT on base metals resulted in the formation of interfacial layers, yielding the degradation of ferroelectric properties. ${ }^{24}$ In particular, aluminium oxide formation could occur between the substrate and the first PZT layer during the heat treatment, leading to oxygen vacancies in the first deposited PZT layers. That could explain the asymmetric loop-observed during poling of samples without $\mathrm{RuO}_{2}$-with the trapping of electrons when positive voltage is applied. ${ }^{25,26}$ Besides, this is also at the origin of the relative high value of coercive field. When $\mathrm{RuO}_{2}$ layer is used, it protects PZT layer from substrate oxidation during crystallization and limits the defects (e.g., oxygen vacancies) at the interface between the substrate and the PZT. Without the $\mathrm{RuO}_{2}$ layer, $P_{r}$ is weak $\left(\sim 8 \mu \mathrm{C} / \mathrm{cm}^{2}\right)$ and $E_{c}$ is high $(\sim 87 \mathrm{kV} / \mathrm{cm})$, for the same applied electric field $(167 \mathrm{kV} / \mathrm{cm})$ at which the hysteresis loop is not saturated. As seen in Fig. 4(b), the remnant polarization increases up to $\sim 25 \mu \mathrm{C} / \mathrm{cm}^{2}$ when $40 \mathrm{~nm}$ thick $\mathrm{RuO}_{2}$ layer is added and $P_{r}$ remains almost constant for higher $\mathrm{RuO}_{2}$ thicknesses. The coercive field is also strongly affected since it is divided by almost 2 with the presence of a $120 \mathrm{~nm}$ thick ruthenium oxide layer. Thus, for these two parameters, $\mathrm{RuO}_{2}$ has a very interesting beneficial effect.

$\mathrm{RuO}_{2}$ influence is also observed on the relative dielectric permittivity, as shown in Fig. 4(c). The $\varepsilon_{r}$ value is $\sim 310$ for PZT on aluminium and increases up to about 550 for the three PZT thin films on $\mathrm{RuO}_{2}$-coated aluminium. These quite low values come from the annealing time and temperature, respectively, shorter and weaker than those commonly used in the literature. ${ }^{7,27,28}$ Higher annealing time or temperature could improve crystallization and so ferroelectric properties, but it would degrade the aluminium foil substrate owing to

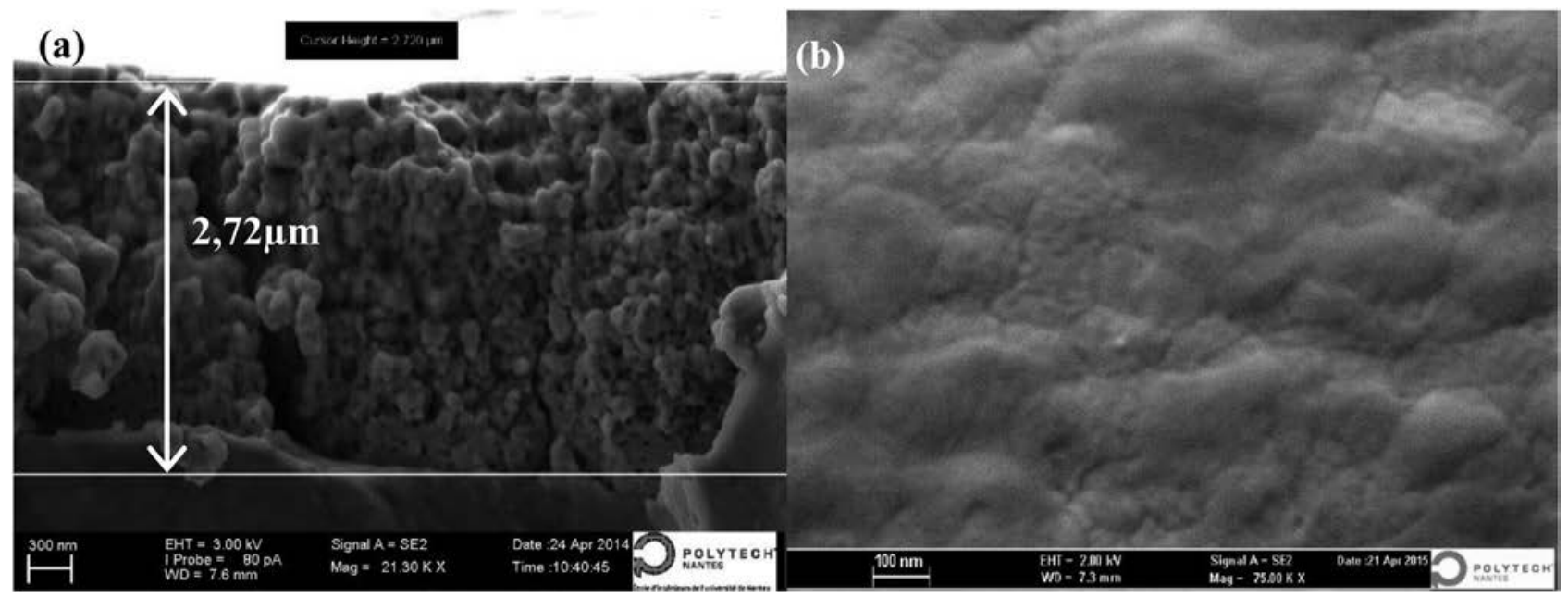

FIG. 3. SEM images of PZT 40/60 deposited onto aluminium substrate. (a) Cross-section and (b) top surface. 
(a)
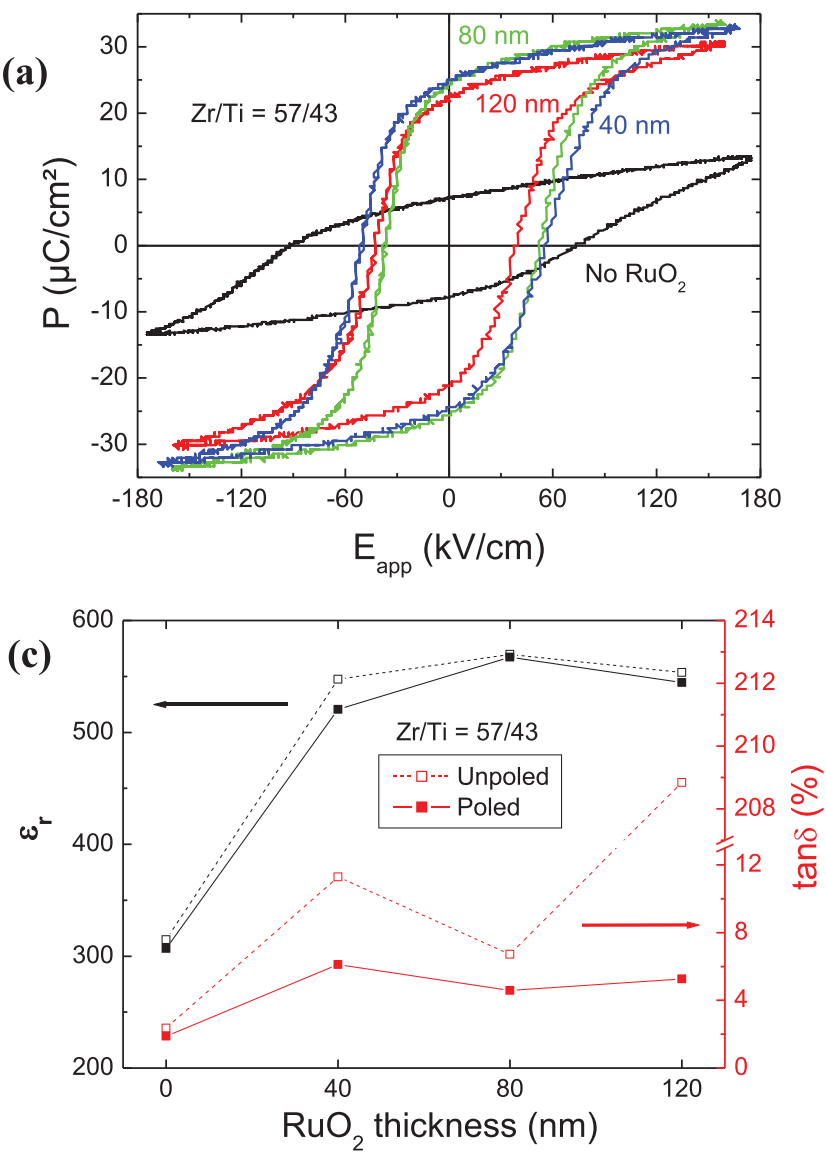

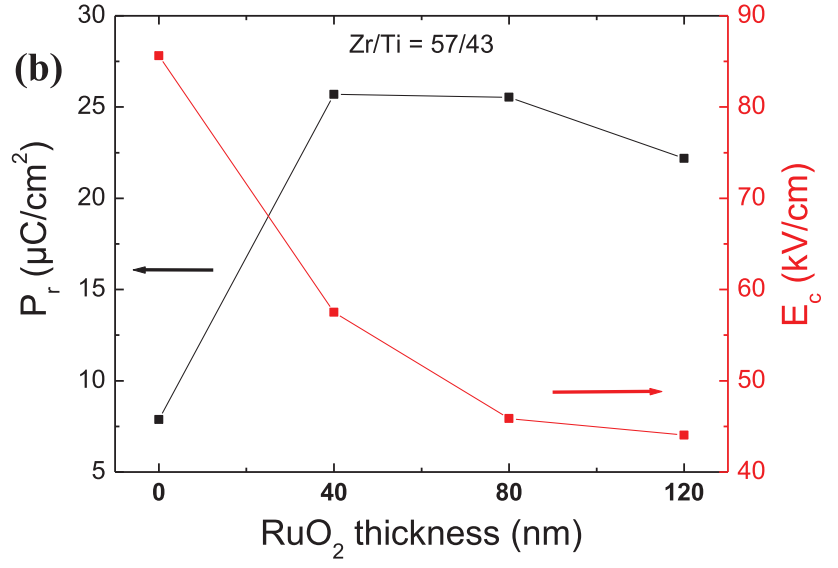

FIG. 4. Ferroelectric and dielectric properties of a $3 \mu \mathrm{m}$-thick PZT 57/43 thin film as a function of RuO $\mathrm{O}_{2}$ thickness: (a) hysteresis loops, (b) remnant polarization $P_{r}$ and coercive field $E_{c}$, and (c) relative dielectric permittivity $\varepsilon_{r}$ and loss factor tan $\delta$ : comparison between poled and unpoled material.

its low thickness $(16 \mu \mathrm{m})$ and melting point $\left(\sim 660^{\circ} \mathrm{C}\right)$. In addition, a more crystallized thin film will lose flexibility and will favour the appearance of cracks. The loss factor value remains roughly the same after the poling step-around 5\%-with and without the oxide layer. During the deposition of PZT, $\mathrm{RuO}_{2}$ may diffuse and create some micrometersized diffusion channels through the PZT layer acting as electrical conduction paths, which could explain the $\tan \delta$ increase observed for PZT on $120 \mathrm{~nm}$ thick $\mathrm{RuO}_{2}$ layer. Consequently, the drastic $\tan \delta$ decrease after the poling step could be explained by a self-healing effect at the top electrode. ${ }^{29}$

This effect seems to be confirmed by the optical microscopy photographs of the top electrode before and after poling (Fig. 5). In fact, those micro-channels are sealed by the local melting of the top surface of the thin film due to electrical breakdown when the electric field is applied during the poling process, as shown in Fig. 5(b). Consequently, the dielectric loss factor is decreased thanks to the self-healing of the electrode.

Finally, this study shows that it is not necessary to coat a $120 \mathrm{~nm}$ thick $\mathrm{RuO}_{2}$ layer, a $40 \mathrm{~nm}$ thick layer is enough to enhance the dielectric and ferroelectric properties. In the following experiments, a $\mathrm{RuO}_{2}$ layer of $40 \mathrm{~nm}$ will be used.

In order to estimate the piezoelectric coefficient, a laser vibrometer was used for measuring the displacement of the free-end of the beam under an applied voltage. The experimental plots of the displacement as a function of frequency and their fits are given in Fig. 6(a) for three different applied voltages. The experimental data are fitted with Eq. $(1)^{30}$

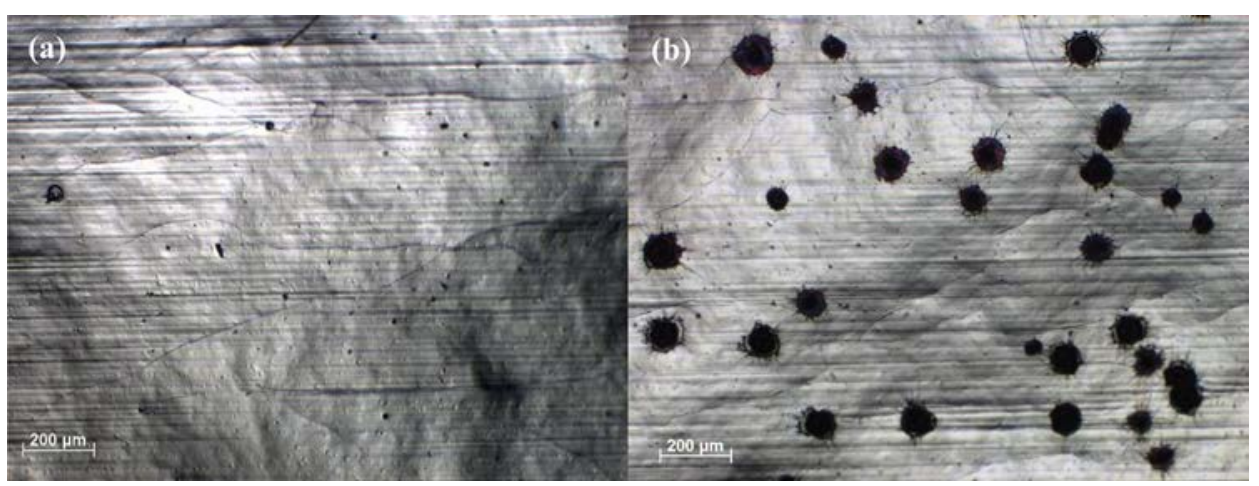

FIG. 5. Optical microscopy photographs of Al top electrode (a) before poling and (b) after poling. Black holes on the electrode after poling correspond to the local melting of the electrode near the conduction channel. 

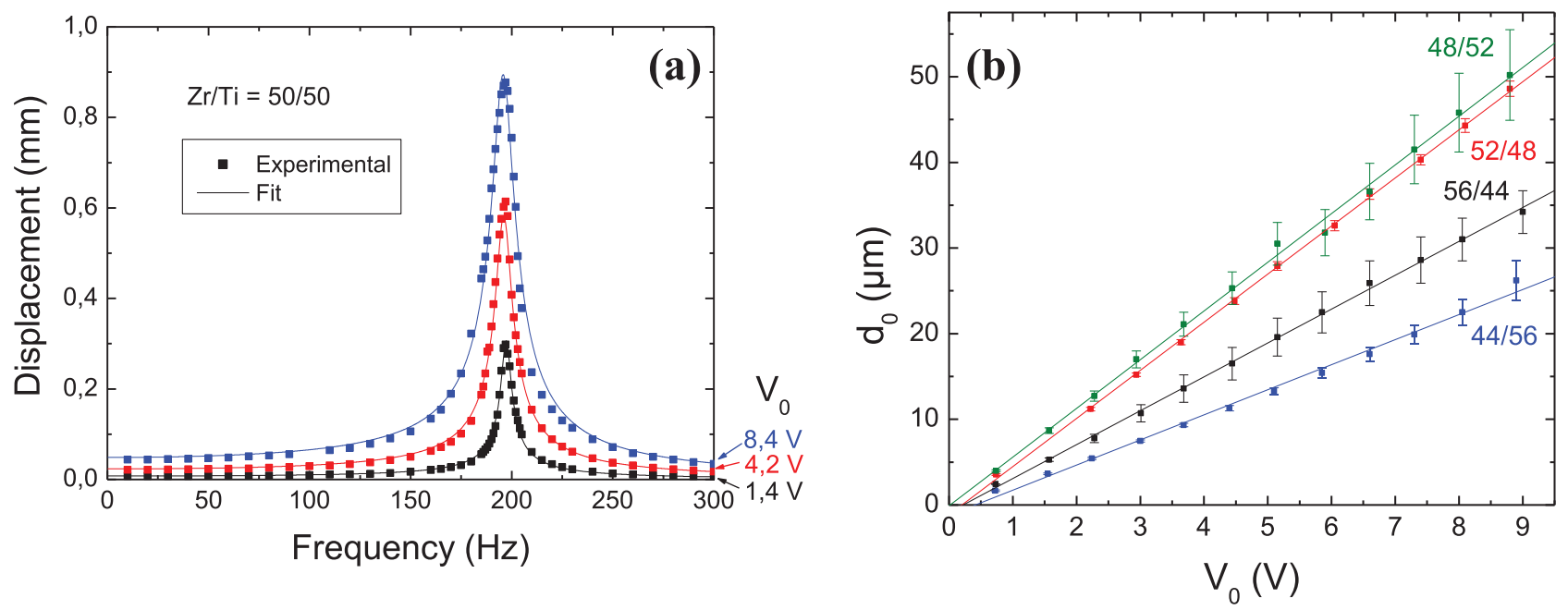

FIG. 6. (a) Tip displacement for PZT 50/50 at different applied voltages. (b) Linear fit of quasistatic displacement $d_{0}$ as a function of the applied voltage for various $\mathrm{Zr} / \mathrm{Ti}$ ratios.

$$
d=\frac{d_{0}}{\sqrt{\left(1-\left(\frac{f}{f_{0}}\right)^{2}\right)^{2}+\frac{1}{Q^{2}}\left(\frac{f}{f_{0}}\right)^{2}}},
$$

where $d_{0}$ is the quasi-static displacement, $f_{0}$, the natural frequency, and $Q$, the quality factor.

A good agreement is observed between experimental data and the fits for each applied voltage. A remarkable point is the order of magnitude of the tip displacement (deflection) at the resonance frequency-around $1 \mathrm{~mm}$-obtained under $8.4 \mathrm{~V}$. This transverse displacement value is very uncommon for bending mode actuators made of PZT thin films and it shows that thin films have a good flexibility. With very similar PZT thicknesses and dimensions of cantilever beam (Table I), Morimoto et al. and Harigai et al. obtained less than $10 \mu \mathrm{m}$ tip displacement. ${ }^{9,31}$

In order to calculate the transverse piezoelectric coefficient $d_{31}$, a linear fit of the quasistatic displacement $d_{0}$ as a function of applied voltage was done, as shown in Fig. 6(b). The fit is realized with Eq. $(2)^{32,33}$

$$
\begin{aligned}
d_{0}= & d_{31} \times \frac{6 s_{a} s_{p} t_{a}\left(t_{a}+t_{p}\right) \times\left(l_{e} l_{b}-\frac{l_{e}^{2}}{2}\right)}{s_{a}^{2} t_{p}^{4}+4 s_{a} s_{p} t_{a} t_{p}^{3}+6 s_{a} s_{p} t_{a}^{2} t_{p}^{2}+4 s_{a} s_{p} t_{a}^{3} t_{p}+s_{p}^{2} t_{a}^{4}} \\
& \times \frac{w_{e}}{w_{b}} \times V_{0}=d_{31} \times \beta \times V_{0}
\end{aligned}
$$

TABLE I. Comparison of PZT cantilever beam tip displacement under an applied voltage around $8.5 \mathrm{~V}$.

\begin{tabular}{lccc}
\hline \hline & $\begin{array}{c}\text { This work: } \\
\text { with/without } \mathrm{RuO}_{2}\end{array}$ & Morimoto et al. ${ }^{9}$ & Harigai et al. ${ }^{31}$ \\
\hline $\mathrm{Zr} / \mathrm{Ti}$ & $40 / 60$ to $60 / 40$ & $52 / 48$ & $53 / 47$ \\
$\mathrm{PZT}$ thickness $(\mu \mathrm{m})$ & 3 & 2.8 & 3.6 \\
Substrate (thickness) & Aluminium & Stainless & Silicium \\
& foil $(16 \mu \mathrm{m})$ & steel $(50 \mu \mathrm{m})$ & $(120 \mu \mathrm{m})$ \\
Length $(\mathrm{cm})$ & 1 & 1.7 & 0.77 \\
Width $(\mathrm{mm})$ & 3 & 4.5 & 1.8 \\
Tip displacement & $0.5-0.9 / 0.8-1.2$ & 0.008 & 0.004 \\
around $8.5 \mathrm{~V}(\mathrm{~mm})$ & & & \\
\hline \hline
\end{tabular}

where $s$ is the inverse of the Young's modulus, $t$ the thickness, $l_{b}, l_{e}$ the lengths and $w_{b}, w_{e}$ the widths of the beam and the electrode, respectively, and $V_{0}$ is the amplitude of the applied voltage. The " $p$ " and " $a$ " subscripts correlate with PZT layer and aluminium substrate, respectively. The slope of the linear fits is divided by $\beta$ to calculate the $d_{31}$ value. This calculation is used in the following to find the $d_{31}$. Here again, the fits are in a good agreement with experimental data.

\section{B. Influence of the PZT thickness on the electrical properties of PZT thin films}

Thickness of PZT 57/43 thin film deposited onto $\mathrm{RuO}_{2} /$ Al was modified from 1.8 to $4.2 \mu \mathrm{m}$. Poling was done as explained before, with an electric field of $167 \mathrm{kV} / \mathrm{cm}$. Both $P_{r}$ and $E_{c}$ are plotted as a function of PZT thickness in Fig. 7(a) and the piezoelectric coefficient of the PZT is given for all the tested thicknesses in Fig. 7(b). It is found that both $P_{r}$ and $E_{c}$ are roughly independent upon the PZT thickness. It seems that the thickness of the PZT layer has no impact on ferroelectric properties. Whatever, the electromechanical conversion depends on piezoelectric properties so the thickness dependence of $d_{31}$ is investigated. For lower thicknesses, i.e., 1.8 and $2.4 \mu \mathrm{m}$, the measured $d_{31}$ values are around $12 \mathrm{pC} / \mathrm{N}$, while for thicknesses above $3 \mu \mathrm{m}, d_{31}$ is multiplied at least by 2 and reaches $27 \mathrm{pC} / \mathrm{N}$ at $4.2 \mu \mathrm{m}$. An abrupt increase in $d_{31}$ is observed when the PZT thickness changes from 2.4 to $3.0 \mu \mathrm{m}$. But for thicknesses under $3.0 \mu \mathrm{m}$, some difficulties appeared in the poling step. Few samples of less than $3.0 \mu \mathrm{m}$-thick were in short-circuit, which could mean that the insulating properties of the first PZT layers are medium. So the weak piezoelectric properties of the low thickness PZT thin layer beam may be explained by the medium quality of the material.

\section{Influence of the $\mathrm{Zr} / \mathrm{Ti}$ ratio on the electrical properties of PZT thin films}

Different $\mathrm{Zr} / \mathrm{Ti}$ ratios were tested for samples with PZT layer of $3 \mu \mathrm{m}$ in thickness deposited onto bare and $40 \mathrm{~nm}$ 

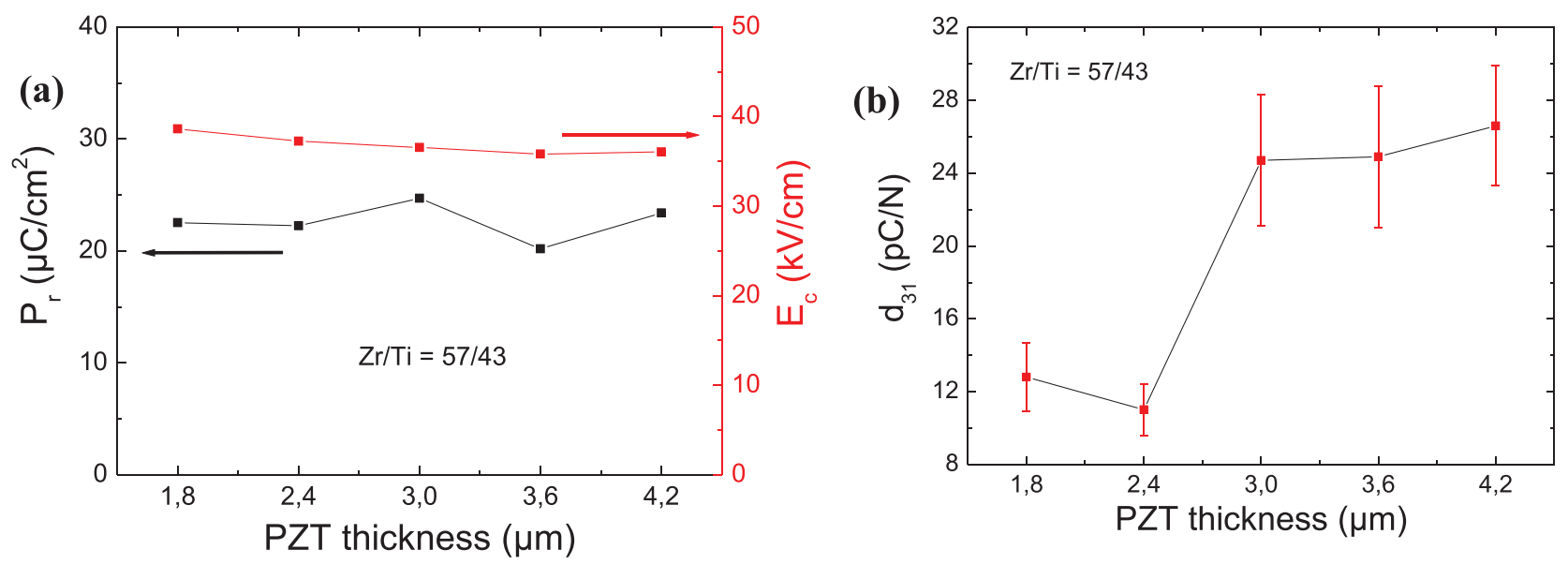

FIG. 7. (a) $P_{r}$ and $E_{c}$ and (b) $d_{31}$ evolution of PZT $57 / 43$ thin film deposited onto $40 \mathrm{~nm} \mathrm{RuO}_{2}$ coated aluminium substrate as a function of PZT layer thickness.

$\mathrm{RuO}_{2}$ coated aluminium foil. This study was carried out to show the influence of $\mathrm{Zr} / \mathrm{Ti}$ ratio on both ferroelectric properties and the transverse piezoelectric coefficient $d_{31}$. To maximize the evaluated properties of PZT thin films with and without $\mathrm{RuO}_{2}$, it was chosen to apply electric field values of $167 \mathrm{kV} / \mathrm{cm} 267 \mathrm{kV} / \mathrm{cm}$, respectively. Under these appropriate electric field strengths, saturated hysteresis loops were obtained.

As shown in Fig. 8(a), for both PZT thin films with/ without $\mathrm{RuO}_{2}$, there is no obvious tendency of the $P_{r}$ and $E_{c}$ variation versus the $\mathrm{Zr}$ content. However, ferroelectric properties are significantly improved with the $\mathrm{RuO}_{2}$ layer, whatever the $\mathrm{Zr} / \mathrm{Ti}$ ratio. As a matter of fact, ferroelectric saturation was reached for all samples with $\mathrm{RuO}_{2}$. Besides, saturation of P-E loops is obtained with an applied electric field of $167 \mathrm{kV} / \mathrm{cm}$, whereas $267 \mathrm{kV} / \mathrm{cm}$ is necessary for the samples without the oxide layer. Moreover, with the intermediate oxide layer, the hysteresis loops are symmetric, and the coercive field is at least divided by 2 . There is a quite improvement of the remnant polarization. From an average value of $14 \mu \mathrm{C} / \mathrm{cm}^{2}$ without $\mathrm{RuO}_{2}$ for the studied $\mathrm{Zr}$ contents, it rises to $24 \mu \mathrm{C} / \mathrm{cm}^{2}$ with a $40 \mathrm{~nm}$ oxide layer. Ferroelectric properties are improved with the intermediate
$\mathrm{RuO}_{2}$ layer and no clear dependence of this improvement upon the $\mathrm{Zr} / \mathrm{Ti}$ ratio could be evidenced, but measurement of the $d_{31}$ remains the principal objective of this study.

The obtained results of $d_{31}$ calculation are plotted in Fig. 8(b). Without $\mathrm{RuO}_{2}, d_{31}$ increases for $0.4<\mathrm{x}<0.48$ and reaches a maximum of $14 \mathrm{pC} / \mathrm{N}$ for PZT compositions with $\% \mathrm{Zr}=52-54$. It is corresponding typically to PZT ceramics compositions of the MPB $(\mathrm{Zr} / \mathrm{Ti}=52 / 48)$ where both tetragonal and rhombohedral phases coexist at room temperature in the phase diagram. ${ }^{17}$ In addition, a shift of the MPB to the high $\mathrm{Zr}$ content is observed for PZT thin films. ${ }^{34}$ When the molar percentage of zirconium gets higher, the transverse coefficient value seems to decrease. This behaviour was already observed in the literature for both thick ${ }^{35}$ and thin PZT films. ${ }^{36}$ However, experimental $d_{31}$ values of PZT on aluminium substrate are lower than those reported in the literature for PZT on silicon ( $\mathrm{Si}, 118.9 \mathrm{pC} / \mathrm{N}$ (Ref. 37)) or stainless steel (SS, $55 \mathrm{pC} / \mathrm{N}$ (Ref. 38)). But the difference could be explained by the originality of the flexible aluminium substrate. Indeed, the PZT thin layer $(3 \mu \mathrm{m}, 92.5 \mathrm{GPa}$ evaluated from Kanno et $a l .{ }^{39}$ ) is not constrained by the uncommon low thickness $(16 \mu \mathrm{m})$ and the weak Young's modulus $(65 \mathrm{GPa})$ of the substrate (commercial aluminium
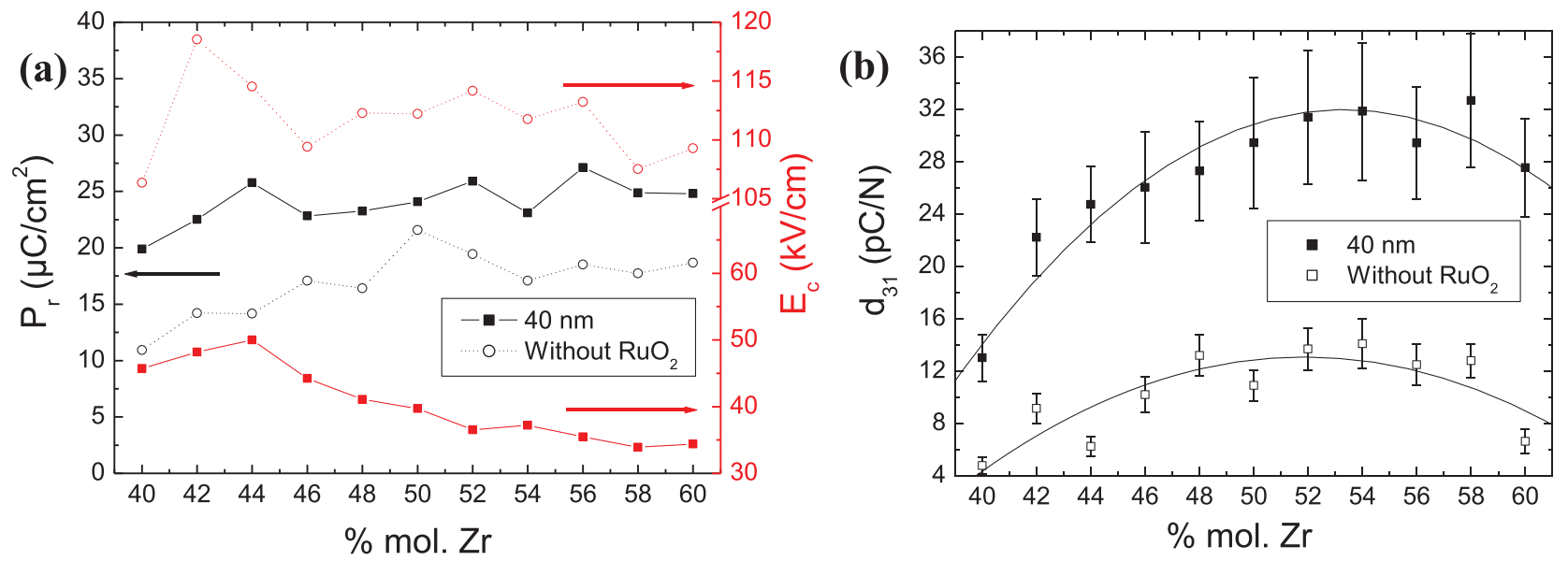

FIG. 8. (a) Variation of the remnant polarization and coercive field as a function of $\mathrm{Zr}$ content. (b) Variation of the transverse piezoelectric coefficient $d_{31}$ as a function of $\mathrm{Zr}$ content. Solid lines are guides for the eyes. Comparison between PZT thin film with and without $\mathrm{RuO}_{2}$. 
foil) like it would be with $\mathrm{Si}(130.2 \mathrm{GPa}$ for $\langle 100\rangle$ oriented silicon) or SS ( $200 \mathrm{GPa})$.

Besides, a large increase of $d_{31}$ is obtained with the intermediate oxide layer. As a matter of fact, it is multiplied by an average factor of 2.7, for the different studied $\mathrm{Zr}$ contents.

As seen before, when the PZT crystallizes in a tetragonal phase $(x<0.48)$, the transverse piezoelectric coefficient increases with increasing $\mathrm{Zr}$ content. With $\mathrm{RuO}_{2}$, the maximum is not observed in the vicinity of the MPB but for the PZT thin film of composition 58/42 $\left(d_{31}=33 \mathrm{pC} / \mathrm{N}\right)$. This maximum is still a little bit lower than $d_{31}$ values of thin films given in the literature. ${ }^{9,40}$ However, in view of potential applications, the low $d_{31}$ values of PZT/Al are compensated by the remarkable flexibility, the associated low working frequencies, and the low cost of fabrication, which render these lightweight PZT thin films promising materials for some applications like gas flow sensing, wearable electronics, or micro-energy harvesting.

Nevertheless, concerning the $\mathrm{Zr} / \mathrm{Ti}$ ratio, it is difficult to choose an optimal composition with the uncertainty of the $d_{31}$ measurement for $\mathrm{Zr}$ content between $52 \%$ and $58 \%$. If we pay attention to the trend of the curve, it seems the maximum $d_{31}$ could be near the MPB, which is a similar trend previously observed without $\mathrm{RuO}_{2}$. However, the optimal composition seems to be shifted towards the rhombohedral phase.

Finally, the $40 \mathrm{~nm} \mathrm{RuO}_{2}$ layer has a real positive impact on ferroelectric and piezoelectric properties of PZT/Al thin films. In fact, this layer acts as a diffusion barrier at the PZTaluminium interface. The density of oxygen vacancieswhich have trapped electrons when a positive field is applied-is reduced with $\mathrm{RuO}_{2}$. So, the real field applied to the PZT layer, for the same amplitude, may be higher when the intermediate $\mathrm{RuO}_{2}$ layer is used.

\section{CONCLUSIONS}

PZT thin films of various compositions and thicknesses were deposited onto bare and $\mathrm{RuO}_{2}$ coated aluminium. Dielectric, ferroelectric, and piezoelectric characteristics were measured on bending mode cantilever beams. Results show the influence of the intermediate oxide layer $\left(\mathrm{RuO}_{2}\right)$ which contributes to reduce the amount of oxygen vacancies in the first deposited PZT layers and improve almost all the studied properties. For a $3 \mu \mathrm{m}$ thick PZT thin film with different $\mathrm{Zr} / \mathrm{Ti}$ ratios, an interfacial $\mathrm{RuO}_{2}$ layer of $40 \mathrm{~nm}$ in thickness yields a large increase of average remnant polarization $P_{r}$ is around $14 \mu \mathrm{C} / \mathrm{cm}^{2}$ to $24 \mu \mathrm{C} / \mathrm{cm}^{2}$, while the average coercive field $E_{c}$ is divided by at least 2 and $d_{31}$ is increased with an average factor of 2.7.

It was found that the optimal material parameters for measurement of $d_{31}$ coefficient are the presence of the $40 \mathrm{~nm}$ thick $\mathrm{RuO}_{2}$ layer and a PZT thickness of $3 \mu \mathrm{m}$. Besides, the $\mathrm{Zr} / \mathrm{Ti}$ ratio must lie between 52/48 and 58/42, which means that PZT compositions on the rhombohedral side of the MPB give the best results. A maximal $d_{31}$ value of $33 \mathrm{pC} / \mathrm{N}$ was obtained for $\mathrm{Zr} / \mathrm{Ti}=58 / 42$.

Finally, the optimal properties of the thin film are of the same order of magnitude than the observed values in the literature. However, a better flexibility-with displacement around $1 \mathrm{~mm}$ under low voltage $(\sim 8 \mathrm{~V})$-is noticed for our films due to the low aluminium substrate thickness and Young's modulus, which is asset for electromechanical applications requiring large displacements induced by low voltage appliance. Such PZT thin film cantilevers may also be of interest for aeroelastic energy harvesting from low frequency vibration. In this sense, future work will be devoted to the direct piezoelectric effect in these recently developed $\mathrm{PZT} / \mathrm{Al}$ thin films.

${ }^{1}$ J. Kymissis, C. Kendall, J. Paradiso, and N. Gershenfeld, in Second International Symposium on Wearable Computing 1998, Digest of Papers (IEEE, 1998), pp. 132-139.

${ }^{2}$ J. J. H. Paulides, J. W. Jansen, L. Encica, E. A. Lomonova, and M. Smit, in IEEE International Electric Machines and Drives Conference 2009, IEMDC09 (IEEE, 2009), pp. 439-444.

${ }^{3}$ R. L. Harne, Mech. Syst. Signal Process. 36, 604 (2013).

${ }^{4}$ A. Chandrakasan, R. Amirtharajah, J. Goodman, and W. Rabiner, in Proceedings of 1998 IEEE International Symposium on Circuits and Systems 1998, ISCAS98 (IEEE, 1998), pp. 604-607.

${ }^{5}$ G. Poulin, E. Sarraute, and F. Costa, Sens. Actuators Phys. 116, 461 (2004).

${ }^{6}$ J. C. Park and J. Y. Park, Ceram. Int. 39, S653 (2013).

${ }^{7}$ Y. B. Jeon, R. Sood, J.-H. Jeong, and S.-G. Kim, Sens. Actuators Phys. 122, 16 (2005).

${ }^{8}$ P. Muralt, M. Marzencki, B. Belgacem, F. Calame, and S. Basrour, Proc. Chem. 1, 1191 (2009).

${ }^{9}$ K. Morimoto, I. Kanno, K. Wasa, and H. Kotera, Sens. Actuators Phys. 163, 428 (2010).

${ }^{10} \mathrm{~S}$. Trolier-McKinstry and P. Muralt, J. Electroceram. 12, 7 (2004).

${ }^{11}$ C. Dagdeviren, B. D. Yang, Y. Su, P. L. Tran, P. Joe, E. Anderson, J. Xia, V. Doraiswamy, B. Dehdashti, X. Feng, B. Lu, R. Poston, Z. Khalpey, R. Ghaffari, Y. Huang, M. J. Slepian, and J. A. Rogers, Proc. Natl. Acad. Sci. 111, 1927 (2014).

${ }^{12}$ M. D. Nguyen, M. Dekkers, H. N. Vu, and G. Rijnders, Sens. Actuators Phys. 199, 98 (2013).

${ }^{13}$ M.-A. Dubois and P. Muralt, Sens. Actuators Phys. 77, 106 (1999).

${ }^{14}$ J. F. Shepard, Jr., P. J. Moses, and S. Trolier-McKinstry, Sens. Actuators Phys. 71, 133 (1998).

${ }^{15}$ J. E. A. Southin, S. A. Wilson, D. Schmitt, and R. W. Whatmore, J. Phys. Appl. Phys. 34, 1456 (2001).

${ }^{16}$ I. Kanno, H. Kotera, and K. Wasa, Sens. Actuators Phys. 107, 68 (2003).

${ }^{17}$ B. Jaffe, W. R. Cook, and H. L. Jaffe, Piezoelectric Ceramics (Academic Press, London, 1971).

${ }^{18}$ B. Noheda, D. E. Cox, G. Shirane, J. A. Gonzalo, L. E. Cross, and S.-E. Park, Appl. Phys. Lett. 74, 2059 (1999).

${ }^{19}$ A. K. Tagantsev and I. A. Stolichnov, Appl. Phys. Lett. 74, 1326 (1999).

${ }^{20}$ S.-H. Kim, J.-S. Yang, C. Y. Koo, J.-H. Yeom, E. Yoon, C. S. Hwang, J.S. Park, S.-G. Kang, D.-J. Kim, and J. Ha, Jpn. J. Appl. Phys., Part 1 42, 5952 (2003).

${ }^{21}$ R. Seveno and D. Averty, J. Sol-Gel Sci. Technol. 68, 175 (2013).

${ }^{22}$ R. Seveno, P. Limousin, D. Averty, J.-L. Chartier, R. Le Bihan, and H. W. Gundel, J. Eur. Ceram. Soc. 20, 2025 (2000).

${ }^{23}$ J. H. Yi, R. Seveno, and H. W. Gundel, Integr. Ferroelectr. 23, 199 (1999).

${ }^{24}$ M. D. Losego, L. H. Jimison, J. F. Ihlefeld, and J.-P. Maria, Appl. Phys. Lett. 86, 172906 (2005).

${ }^{25}$ B. G. Chae, C. H. Park, Y. S. Yang, and M. S. Jang, Appl. Phys. Lett. 75, 2135 (1999).

${ }^{26}$ Q. Zou, H. E. Ruda, B. G. Yacobi, K. Saegusa, and M. Farrell, Appl. Phys. Lett. 77, 1038 (2000).

${ }^{27}$ M. H. M. Zai, A. Akiba, H. Goto, M. Matsumoto, and E. M. Yeatman, Thin Solid Films 394, 96 (2001).

${ }^{28}$ Y.-L. Tu, M. L. Calzada, N. J. Phillips, and S. J. Milne, J. Am. Ceram. Soc. 79, 441 (1996).

${ }^{29}$ N. Klein, IEEE Trans. Electron Devices 13, 788 (1966).

${ }^{30}$ F. K. Kneubühl, Oscillations and Waves (Springer, Berlin, 1997).

${ }^{31}$ T. Harigai, H. Adachi, and E. Fujii, J. Appl. Phys. 107, 096101 (2010).

${ }^{32}$ J. G. Smits and W.-S. Choi, IEEE Trans. Ultrason. Ferroelectr. Freq. Control 38, 256 (1991). 
${ }^{33}$ J. G. E. Gardeniers, A. G. B. J. Verholen, N. R. Tas, and M. C. Elwenspoek, J. Korean Phys. Soc. 32, S1573 (1998).

${ }^{34}$ S. Hoon Oh and H. Jang, Phys. Rev. B 62, 14757 (2000).

${ }^{35}$ E. Boucher, B. Guiffard, L. Lebrun, and D. Guyomar, Ceram. Int. 32, 479 (2006).

${ }^{36}$ N. Ledermann, P. Muralt, J. Baborowski, S. Gentil, K. Mukati, M. Cantoni, A. Seifert, and N. Setter, Sens. Actuators Phys. 105, 162 (2003).
${ }^{37}$ M. Dekkers, H. Boschker, M. van Zalk, M. Nguyen, H. Nazeer, E. Houwman, and G. Rijnders, J. Micromech. Microeng. 23, 025008 (2013).

${ }^{38} \mathrm{~S}$. Umemiya, M. Hida, T. Aoki, and M. Kondo, in 15th IEEE International Symposium on Applications of Ferroelectrics 2006, ISAF06 (IEEE, 2006), pp. 318-321.

${ }^{39}$ I. Kanno, S. Fujii, T. Kamada, and R. Takayama, Appl. Phys. Lett. 70, 1378 (1997).

${ }^{40}$ D.-M. Chun, M. Sato, and I. Kanno, J. Appl. Phys. 113, 044111 (2013). 